\title{
A double blind, placebo controlled trial of intravenous methylprednisolone in systemic lupus erythematosus
}

\author{
C G MACKWORTH-YOUNG, J DAVID, S H MORGAN, AND \\ G R V HUGHES
}

From the Rheumatology Unit, Department of Medicine, Hammersmith Hospital, London

SUMmARY A double blind, placebo controlled trial was performed in 25 patients to study the use of intravenous methylprednisolone (IVMP) in the treatment of active systemic lupus erythemato sus (SLE). The trial examined the additive effect of IVMP on a background of conventional oraP steroid treatment. Patients were followed up for six months. The results showed a trend towardsmore consistent overall improvement in the first two weeks after IVMP administration compare ${ }^{\circ}$ with placebo, but this difference was not maintained at one month or subsequently. They alsosuggested a quicker resolution of hypocomplementaemia in the treatment group. Othe parameters of disease activity showed no difference. Side effects were generally mild and were similar in incidence between the two groups. Thus it is concluded that IVMP may improve initiap suppression of active lupus in some patients when added to conventional oral steroid treatment but that this additional benefit is not maintained; IVMP is, however, a relatively safe treatmeno when used in this way.

Key words: pulse therapy, steroid.

High dose intravenous methylprednisolone (IVMP) was first used for treating SLE in the mid-1970s. ${ }^{1}$ The principal rationale for its use was to achieve a higher therapeutic effect than conventional oral steroids while minimising toxicity. Initial results were promising, and there followed a large number of reports on the use of IVMP treatment for patients with SLE with and without renal involvement (reviewed in ref. 2). Most of these were uncontrolled studies; success appeared to be variable. Kimberley et al found that 12 out of 34 patients with lupus nephritis improved after IVMP treatment, ${ }^{3}$ and Isenberg et al reported that at 12 weeks after IVMP treatment eight out of 20 patients with active SLE showed a sustained partial improvement. ${ }^{4}$ Similarly, Ponticelli et al noted good results in 25 patients with lupus nephritis. ${ }^{5}$ Edwards et al, however, failed to show a clinically significant difference between $1 \mathrm{~g}$ and $100 \mathrm{mg} \mathrm{IVMP}$ in severe or persistently symptomatic SLE, suggesting that

Accepted for publication 3 November 1987.

Correspondence to Dr C G Mackworth-Young, Rheumatology Unit, Department of Medicine, Hammersmith Hospital, Ducane Road, London W12 0HS. the use of very large doses of methylprednisolone produced little therapeutic increment over consider ably lower doses. ${ }^{6}$ Liebling et al performed a smals double blind, placebo controlled trial of IVMP in SLE nephritis. They gave $1 \mathrm{~g}$ of IVMP on three consecutive days monthly for one year and demonstrated a better maintenance of renal function in the treatment group. ${ }^{7}$ A patient from our own clinic has been described, however, whose thrombocytopenia showed a diminishing response to repeated IVMP administration. ${ }^{8}$ And in a group of children with diffuse proliferative lupus nephritis IVMP produce $\mathbb{R}$ a more rapid improvement of glomerular filtratior rate than high dose oral prednisolone treatment, buR it had no better effect on renal function in the lons term. ${ }^{9}$

The purpose of the present study was to examine the effect of a single course of IVMP in moderatel ${ }^{\circ}$ or severely ill patients with SLE by a placeb他 controlled, double blind trial. To maintain adequate्ల treatment for the placebo group the trial was designed to look at the effect of adding IVMP to the dose of oral prednisolone normally used to treag such patients; if IVMP is effective because of the्巳 
bolus administration of very high doses of steroid, then an additive effect should be seen. Our results suggest that there may be an early improved response with IVMP, but that this trend is not apparent after one month. They do, however, indicate that IVMP is a generally safe treatment.

\section{Patients and methods}

Patients attending the rheumatology unit, Hammersmith Hospital, between 1982 and 1986 were entered into the study. Entry criteria included an age between 14 and 65 years and the presence of SLE severe enough to warrant the administration of $40 \mathrm{mg}$ or more of oral prednisolone a day. The presence of SLE was defined according to the revised American Rheumatism Association criteria. ${ }^{10}$

Patients underwent an initial assessment (day 0), which included a full history and examination, details of current treatment, and a range of blood tests, including full blood count, urea and electrolytes, glucose, liver function tests, serum calcium, phosphate, total protein, albumin and total immunoglobulin levels, antinuclear factor, DNA binding (Farr assay), antibodies to extractable nuclear antigens, latex test, complement levels, erythrocyte sedimentation rate, and $\mathrm{C}$ reactive protein. An overall assessment of disease activity was made based on these clinical and laboratory findings and graded as follows: 0 , inactive; 1 , mild; 2 , moderate; 3 , severe; 4 , life threatening. Patients with grade 0 had no symptoms attributable to activity of their disease. Those with grade 1 had evidence of mild disease activity but, as with those in grade 0 , did not have active neurological or renal disease. Those in grade 2 had definitely active disease requiring steroid treatment. Grades 3 and 4 represented disease which would normally be treated with high dose steroids or immunosuppression, or both. All subjects entered the trial with grade 2,3 , or 4 disease, with the exception of one patient, whose only significant manifestation was a profound leucopenia (see 'Results') and whose disease activity was assessed as grade 1 .

All subjects then received IVMP or placebo on a double blind basis. IVMP $(1 \mathrm{~g})$, or for the placebo group an equivalent volume of diluent, was administered over four hours in $500 \mathrm{ml}$ of normal saline on three consecutive days. In addition, treatment with oral prednisolone was started at between 40 and 60 mg a day.

The patients were followed up for six months. A full examination and repeat blood tests were performed at each clinic visit. An overall assessment of the patient was made and any change in the category of disease severity noted. The doses of oral steroids and of other drugs were adjusted accordingly; in particular, other disease modifying agents, such as cytotoxic drugs, were added if required.

At the end of six months an assessment as to overall outcome for each patient was made.

\section{S T A T IS T I C S}

Results were analysed with the $\chi^{2}$ test and Student's $t$ test.

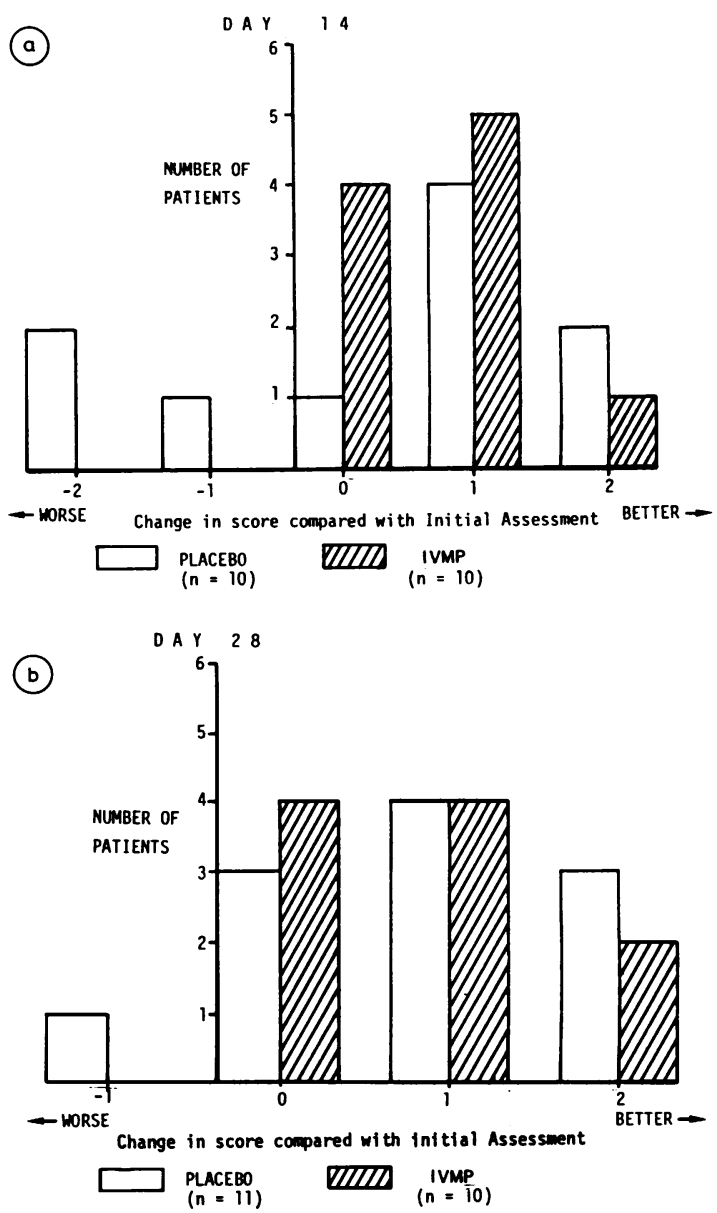

Fig. 1 Changes in overall assessment score (a) at day 14 and (b) at day 28, in both cases compared with day 0 . The horizontal axis represents the change in assessment score. Each vertical bar represents the number of individuals in each group with the same improvement or deterioration in assessment score. Thus, for example (Fig. 1a), five out of 10 patients in the IVMP group who were assessed at 14 days had improved their assessment score by one point compared with day 0 while four out of the 10 patients in the placebo group had done so. 


\section{Results}

\section{PATIENTS}

Twenty five patients were studied, all of them female. Twelve were randomly assigned to the IVMP treatment group (age range 17-61 years, mean 28.9). Thirteen were assigned to the placebo control group (age range 15-55 years, mean $36 \cdot 1$ ); one of these individuals was entered twice into the study and received placebo both times.

\section{OVERALL ASSESSMENT}

Overall assessments of the patients were performed at clinic visits during the follow up period. Each assessment was expressed as the grade of severity of disease (see 'Patients and methods'), and this was compared with the severity grade at the initial assessment. Table 1 provides a summary of these and other results.

There was a trend towards greater improvement in the IVMP treatment group compared with the placebo control group at 14 days. Fig. 1a shows thaE of the 10 patients in the treatment group who were assessed at 14 days all of them showed eithe? improvement or no change in their disease severityes grade compared with the immediate pretreatmen $\vec{b}$ period. By comparison, three of the 10 patients inthe control group assessed at this time showed deterioration in their disease severity grade, two of them by two points. The difference between the two groups was not statistically significant, however, and by 28 days the results (again compared with the pretreatment period) were similar in both groups of patients (Fig. 1b). The same was true at subsequeng

Table 1 Summary of clinical and laboratory data on all patients

\begin{tabular}{|c|c|c|c|c|c|c|c|c|c|c|c|c|}
\hline \multirow{3}{*}{$\begin{array}{l}\text { Patient } \\
\text { No }\end{array}$} & \multirow{3}{*}{$\begin{array}{l}\text { Age } \\
\text { (years) }\end{array}$} & \multirow{3}{*}{$\begin{array}{l}\text { Age at } \\
\text { initial } \\
\text { diagnosis } \\
\text { of SLE } \\
\text { (years) }\end{array}$} & \multirow{3}{*}{$\begin{array}{l}\text { Duration } \\
\text { of present } \\
\text { flare } \\
\text { (weeks) }\end{array}$} & \multirow{2}{*}{\multicolumn{2}{|c|}{$\begin{array}{l}\text { Overall assessment } \\
\text { grade }\end{array}$}} & \multicolumn{5}{|c|}{ Systems involved $t$} & \multirow{2}{*}{\multicolumn{2}{|c|}{$\begin{array}{l}\text { Laboratory } \\
\text { results } \dagger\end{array}$}} \\
\hline & & & & & & \multirow{2}{*}{$\overline{\text { Skin }}$} & \multirow{2}{*}{ Joints } & \multirow{2}{*}{$R S \ddagger$} & \multirow{2}{*}{ CNS $\ddagger$} & \multirow{2}{*}{ Kidneys } & & \\
\hline & & & & At day & OAt day 28 & & & & & & $D N A b \ddagger$ & $C 3 \mp$ ఠ \\
\hline \multicolumn{13}{|c|}{ IVMP group } \\
\hline 4 & 61 & 61 & 6 & 2 & 2 & & + & & & & & బొ \\
\hline 5 & 33 & 27 & 25 & 2 & 2 & + & & & & & $95^{*}$ & ำ \\
\hline 6 & 41 & 35 & 6 & 3 & 2 & $+^{*}$ & + & & & & $95^{*}$ & 은 \\
\hline 10 & 24 & 24 & 3 & 3 & 1 & + & + & & & & $95^{*}$ & $18^{*} \overline{\mathrm{C}}$ \\
\hline 11 & 32 & 25 & 16 & 2 & 2 & & & & & $+^{*}$ & & 3 \\
\hline 12 & 22 & 20 & 1 & 4 & 3 & $+^{*}$ & $+^{*}$ & + & & & $36^{*}$ & $30 *$ \\
\hline 14 & 29 & 19 & 20 & 3 & 3 & & $+^{*}$ & & + & & & $57 \frac{*}{0}$ \\
\hline 16 & 20 & 16 & 3 & 3 & 2 & $+^{*}$ & & & & & & $\stackrel{-}{*}$ \\
\hline 18 & 26 & 26 & 6 & 2 & 2 & $+^{*}$ & + & & & & 51 & ฏ \\
\hline 19 & 17 & 17 & 8 & 3 & 2 & $+^{*}$ & $+^{*}$ & & $+^{*}$ & & & 으. \\
\hline 20 & 20 & 18 & 8 & 3 & 1 & & & & & $+^{*}$ & $79^{*}$ & 윽 \\
\hline 21 & 20 & 14 & 4 & 3 & $\S$ & + & + & & & & 61 & $46 \stackrel{3}{3}$ \\
\hline \multicolumn{13}{|c|}{ Placebo group } \\
\hline 1 & 36 & 27 & 8 & 3 & 2 & $+^{*}$ & & & + & & 65 & \\
\hline 2 & 42 & 26 & 20 & 2 & 2 & $+^{*}$ & $+^{*}$ & & & & $85^{*}$ & 윽 \\
\hline 3 & 34 & 23 & 8 & 2 & 2 & & & & & + & & $D$ \\
\hline 7 & 43 & 25 & 1 & 3 & 1 & $+^{*}$ & $+^{*}$ & & $+^{*}$ & & $94^{*}$ & ర \\
\hline 8 & 34 & 23 & 2 & 2 & 1 & $+^{*}$ & & & + & & 87 & $24 三$ \\
\hline 9 & 24 & 16 & 2 & 3 & $\|$ & & + & & + & & 65 & N \\
\hline 13 & 55 & 48 & 1 & 2 & 1 & $+^{*}$ & & & & & & \\
\hline 15 & 36 & 31 & 12 & 3 & 1 & & $+^{*}$ & $t^{*}$ & $+^{*}$ & & $97^{*}$ & N \\
\hline 17 & 36 & 26 & 10 & 3 & 1 & & $+^{*}$ & $+^{*}$ & + & & $94^{*}$ & N \\
\hline 22 & 35 & 24 & 12 & 2 & 1 & + & & & & + & 80 & 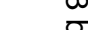 \\
\hline 23 & 38 & 36 & 6 & 2 & 1 & & $+^{*}$ & & & & $93^{*}$ & 우 \\
\hline 24 & 15 & 10 & 3 & 2 & 2 & & + & & & & $58^{*}$ & 550 \\
\hline 25 & 32 & 23 & 52 & 1 & 2 & & & & & & $97^{*}$ & $<10 \frac{ᄃ}{\Phi}$ \\
\hline 26 & 46 & 44 & 12 & 3 & 2 & $+^{*}$ & + & + & & & 98 & 虫 \\
\hline
\end{tabular}

†Under 'Systems involved' and 'Laboratory results' only abnormal findings on day 0 are recorded. +indicates an abnormality due to active SLE; *indicates that an abnormality had shown significant improvement by day 28 .

$\$ R S=$ respiratory system; CNS=central nervous system; DNAb=DNA binding and is recorded as a percentage (normal=30); 33 activit is recorded as a percentage of normal human plasma (normal range 60-130).

\$Patient 21 was not assessed on day 28; at two months there was little change in skin and joint involvement clinically but a return to normaf of $\mathrm{C3}$ activity; the overall assessment grade was 2 .

||Patient 9 developed an atopic reaction on day 1 (see 'Adverse reactions'); subsequent follow up was therefore not carried out โPatient $22-$ no overall assessment was made on day 28. 
assessments, including the final one at six months. At this time all surviving patients who were assessed had disease activity of either grade 1 or grade 2 .

\section{CLINICAL SUBSETS}

Table 1 summarises the clinical results.

Eight patients in the IVMP group and seven in the placebo group had active skin or oral mucosa involvement (e.g. butterfly rash, discoid rash, vasculitic lesions, or mouth ulcers), of whom seven and six respectively were assessed at 28 days, when five of the IVMP and six of the placebo group showed improvement. Corresponding figures for active joint involvement (arthralgia, arthritis, or tendinitis) were comparable: seven in the IVMP and seven in the placebo group were affected (excluding patients 9 and 21 who were not assessed on day 28), of whom three and five respectively showed significant improvement at 28 days.

Initially, one patient treated with IVMP and three treated with placebo had respiratory system involvement (pleurisy or parenchymal lung disease, or both). Of these, only two in the placebo group showed significant improvement at 28 days.

At the start of the study two patients from the IVMP group and six from the placebo group had neurological or psychiatric abnormalities (e.g. peripheral nerve lesions, stroke, or depression, or both); at 28 days one patient from the IVMP group and two from the placebo group had improved (one of the patients in the placebo group dropped out of the study because of an atopic reaction-see below).

Two patients from each group had renal disease with raised serum creatinine levels at the beginning of the study. Those in the IVMP treatment group (patients 11 and 20) had creatinine levels of 237 and $281 \mathrm{nmol} / \mathrm{l}$ respectively; these returned to normal levels at two months. One in the placebo group (patient 22) had an initial creatinine level of 159 $\mathrm{nmol} / \mathrm{l}$; this showed little subsequent change. The other (patient 3 ) had severe renal failure, with a serum creatinine on day 0 of $811 \mathrm{nmol} / \mathrm{l}$. This fell to $588 \mathrm{nmol} / \mathrm{l}$ by day 28 , but subsequently showed a gradual rise.

\section{LA B ORATORY RESULTS}

There were insufficient patients with initial haematological abnormalities to allow for comparison between the treatment and placebo groups of the response of these abnormalities during the follow up period. In view of the tendency of steroids to induce a neutrophilia it was not possible to use the response of a leucopenia as a marker for the efficacy of treatment. One patient (25) had a profound leucopenia (white cell count $1.2 \times 10^{9} / 1$ ) on day 0 . This, together with a moderate anaemia (haemoglo- bin $73 \mathrm{~g} / \mathrm{l}$ ) was her only major feature and the reason for entry into the trial. She was otherwise clinically barely symptomatic and was receiving oral prednisolone and hydroxychloroquine only. On days $3,7,14$, and 28 her white cell count was $1 \cdot 3,0 \cdot 9,2 \cdot 6$, and $3.4 \times 10^{9} / 1$ respectively. The anaemia showed little change in the first three months.

Comparison of DNA binding measurements showed no significant difference between the patient groups. Seven patients in the IVMP group and 12 in the placebo group had raised levels at day 0 . In both groups there tended to be a fall by one month (Table 1), which was subsequently sustained (Fig. 2). Results of erythrocyte sedimentation rate (ESR)

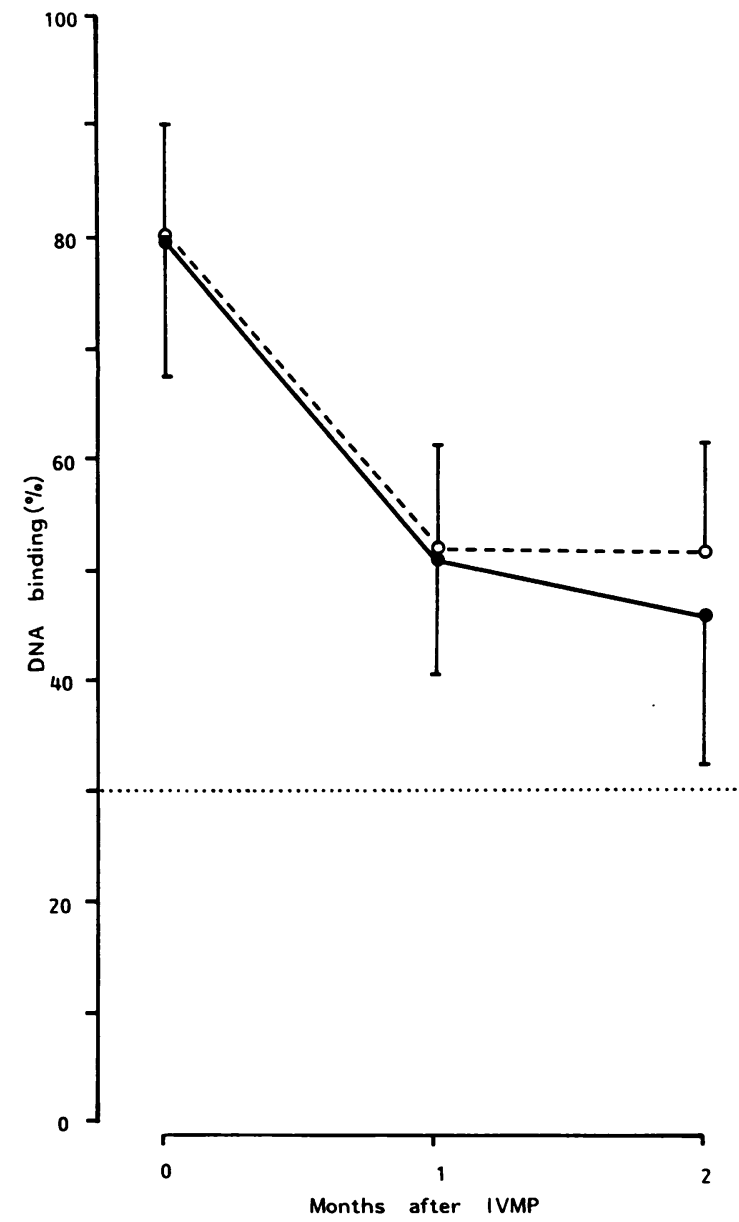

Fig. 2 Mean DNA binding measurement for patients in the IVMP (- - ) and placebo (- - - - - ) groups at days 0 and 28 and at two months. The horizontal dotted line at $30 \%$ DNA binding represents the upper limit of normal. 
estimations followed a similar trend (data not shown).

A total of seven patients had low C3 levels at the start of the study (Table 1). Four of these were in the treatment group; during the first two months of the follow up period the $\mathrm{C} 3$ level normalised in three of them and improved in the fourth. In the three patients in the placebo group the $\mathrm{C} 3$ level normalised in one but was unchanged in the other two. $\mathrm{CH}_{50}$ measurements in all of these individuals produced similar results. There was thus a distinct trend among initially $\mathrm{C} 3$ or $\mathrm{CH}_{50}$ depleted patients to respond better in terms of complement levels if they were in the treatment rather than the control group.

ORAL DRUG DOSAGE

Another method of assessing the response to IVMP treatment was to compare the oral prednisolone doses used in the treatment and placebo groups during the follow up period. The prednisolone dose was adjusted in each individual case in the normal way, according to the clinical and laboratory findings at the time. Fig. 3 shows that there was no significant difference between the doses of oral

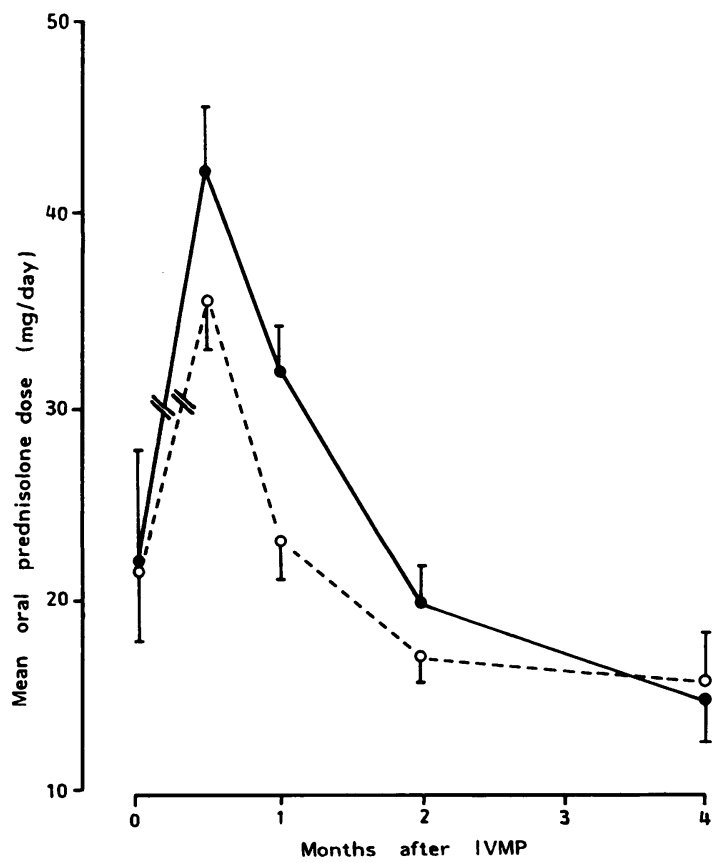

Fig. 3 Mean oral prednisolone doses for patients in the IVMP (-) and placebo (- - - - - groups at days 0 , 14 , and 28 and at two and four months. In all individuals the oral prednisolone dose was increased on day 1 to between 40 and $60 \mathrm{mg} /$ day; this is not indicated on the figure.

prednisolone received by the two patient groups; in? both cases the average dose fell exponentially from $\overrightarrow{\overrightarrow{\mathrm{F}}}$ the initial high level at the start of the study to an average of around $15 \mathrm{mg}$ a day by four months.

Similarly, there was little difference in the use ofe other disease modifying agents. Fig. 4 shows that the number of patients receiving hydroxychloroquine 0 mepacrine, azathioprine, and cyclophosphamides was similar in the two groups before IVMP oro placebo treatment, at days 14 and 28, and at two months.

ADVERSE REACTIONS AND OTHER MAJOR MEDICAL EVENTS

Table 2 lists the adverse reactions and other majore medical events which occurred during the study One individual in the control group developed a rash of rapid onset after the first injection; this was presumed to be due to the diluent, and the patients was taken out of the study.

Two patients developed diabetes mellitus (as $\overrightarrow{0}$ determined by a plasma blood sugar level highepo than $15 \mathrm{mmol} / \mathrm{l}$ ) one (control group) on day 3 and the other (treatment group) at two months. Both

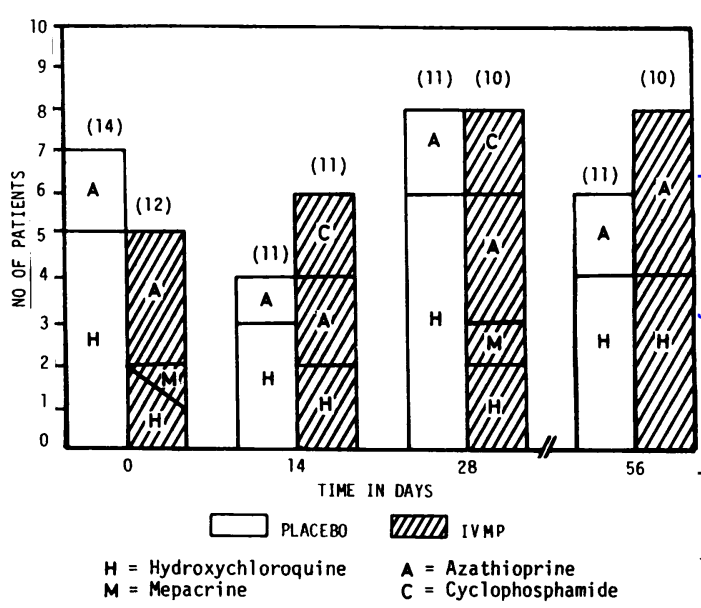

Fig. 4 Concurrent non-steroidal treatment for SLE in patients in the IVMP and placebo groups days 0, 14, and 28 , and at two months. Each vertical bar indicates the number of patients in the group receiving such treatment, and is composed by adding the numbers of individuals taking each drug. The figure above each bar indicates the number of patients assessed at that particular time. Thus for example, of the 14 patients in the placebo group assessed at day 0 , five were taking hydroxychloroquine, and two were taking azathioprine; at the same time three out of 12 patients in the IVMP group were taking azathioprine and two were taking hydroxychloroquine, one of whom was also taking mepacrine. 
Table 2 Major medical events and adverse reactions in patients in the IVMP and placebo groups

\begin{tabular}{lll}
\hline Event & No of cases & Time \\
\hline IVMP group & & \\
Abscesses/cellulitis & 1 & 2 months \\
Diabetes mellitus & 1 & 2 months \\
Marked Cushingoid features & 1 & 3 months \\
Death & 1 & $41 / 2$ months \\
Placebo group & & \\
Allergic reaction & 1 & Day 1 \\
Diabetes mellitus & 1 & Day 3 \\
Marked Cushingoid features & 1 & 1 month \\
Shingles & 1 & 5 months \\
Portal vein thrombosis & 1 & 5 months \\
\hline
\end{tabular}

these patients had had slightly raised blood sugar levels on day 0 , and the latter received high doses of oral prednisolone in the two months before the detection of frank diabetes.

One patient in each group developed marked Cushingoid features; both of these continued to receive high oral prednisolone doses during the first month.

One individual in the treatment group developed abscesses in the thigh and buttock at two months; her disease had previously been characterised by recurrent infections, however, including septicaemia.

One death occurred. This patient, who was in the treatment group, died at $4 \frac{1}{2}$ months of uncontrolled cerebral lupus, manifest as intractable seizures. Between day 28 and two months the patient had had her care transferred to another hospital, and was therefore not assessed for the study after this time.

Patients were not asked about symptoms of metallic taste or flushing at the time of IVMP/ placebo treatment as these side effects are well described, and knowledge of them might have compromised the objectivity of the trial. No patient developed hypotension after IVMP/placebo infusion.

There was no significant difference between the two groups in weight or diastolic blood pressure either on day 0 or at one month.

\section{Discussion}

This study is the largest double blind trial to date of IVMP in the treatment of moderate or severe SLE. Previous reports have been largely anecdotal or uncontrolled (reviewed by Kimberley ${ }^{2}$ ). Despite early encouraging results more recent studies have demonstrated conflicting or equivocal evidence for the improved efficacy of this treatment over conven- tional oral prednisolone. Our study aimed to examine this point more rigorously.

Because of the need to maintain adequate steroid treatment in the placebo treated group, and to be able to adjust treatment during the six month follow up period, it was felt necessary to give both IVMP and placebo treated patients oral prednisolone in the conventional way. The study therefore examined the additive effect of IVMP upon a background of oral prednisolone, starting at between 40 and $60 \mathrm{mg}$ a day. This is a relatively small dose of steroid compared with $1 \mathrm{~g}$ of methylprednisolone, and we therefore felt that if a short course of high dose steroids does have a significantly better effect upon active SLE than conventional treatment then a background dose of $40-60 \mathrm{mg}$ a day of prednisolone should not mask this. This approach had an advantage for assessment: disease activity in the follow up period was assessed not only by individual clinical, haematological, biochemical, and serological parameters (many of which were guides to activity in only a few patients) but also by the alterations made in drug treatment.

The results showed a trend towards a better overall response in the first fortnight in the group of patients treated with IVMP, as judged by overall clinical assessment. This was no longer seen at one month or subsequently. In the case of other markers of disease activity more specific comparison between groups was more difficult as the heterogeneity of SLE resulted in numbers of patients with a particular abnormality being small. There was a trend for skin and joint symptoms to improve more readily in the treatment group, but this was not statistically significant. Among the few patients who had initial hypocomplementaemia, however, there was a more distinct trend to respond better in terms of complement levels if they were in the IVMP treatment group. In the case of other parameters, such as ESR and DNA binding, there was no discernible difference between the treatment and placebo groups. There was also no significant difference between the two groups in oral prednisolone dosage during the follow up period, or in the introduction of other disease modifying drugs.

Thus it appears that IVMP may have an increased therapeutic effect when added to conventional oral prednisolone, a result suggested by an earlier uncontrolled trial in Italy. ${ }^{5}$ The numbers of patients in our study do not allow us to conclude how statistically significant or uniform this may be, however. Furthermore, any such effect seems to be relatively short lived, a finding similar to that of Barron et al in a study of IVMP in childhood lupus nephritis. ${ }^{9}$ One way to overcome this could be to give patients repeated doses of IVMP. In two 
studies this was performed at monthly intervals, with encouraging results at six months ${ }^{11}$ and a year. ${ }^{7}$ Another report, however, suggested a loss of efficacy of IVMP with repeated administration."

There was little overall difference in side effects seen between the treatment and control groups. Two patients developed overt diabetes mellitus, but in both cases this could be ascribed to the oral prednisolone. The development of abscesses and cellulitis in one patient at two months and the death of another at $41 / 2$ months did not seem directly attributable to IVMP. The development of Cushingoid features and the changes in weight and diastolic blood pressure were not significantly different between the two groups. Thus our findings confirm previous reports that IVMP is a relatively safe treatment when given in the way described here.

We cannot exclude the possibility that the oral prednisolone in our patients masked the beneficial effects of IVMP. and that the latter when given alone might have produced similar or increased disease suppression with diminished side effects. Our findings do suggest that IVMP may confer an added initial benefit when used in conjunction with conventional high dose oral prednisolone treatment. though the differences were insufficiently striking for any firm conclusions to be drawn. IVMP does appear to be a safe treatment for active SLE, both in the short and medium term.

The authors wish to thank Upjohn l.td. England for kindly providing IVMP and placebo preparations. and Mrs Caroline Hesketh for excellent secretarial assistance.

\section{References}

1 Catheart E S. Idelson B A. Scheinberg M A. Couser W G. Beneficial effects of methylprednisolone "pulse" theraps in $\frac{\bar{\rho}}{\bar{\sigma}}$ diffuse proliferative lupus nephritis. Lancet 1976: i: 163-6.

2 Kimberles R P. Pulse methulprednisolone in SLE. (lin Rheum Dis 1982: 8: 261-7s.

3 Kimberley R P. Lockshin M D Sherman R L McDougal J S Inman R D. Christian C L. High dose intravenous methylpred-? nisolone pulse therapy in systemic lupus erythematosus. $A m J$ Med 1981: 70: 817-23.

4 Isenherg D A. Morrow W J W. Snaith M L. Methylprednisolone pulse therapy in the treatment of systemic lupus erythematosus. Ann Rheum Dis 1982: 41: 4.37-51.

5 Ponticelli C. Zucchelli P. Banfi G. et al. Treatment of diffuse proliferative lupus nephritis by intravenous high-dose methrlprednisolone. () J Med 1982: 201: 16-24.

6 Edwards J C W. Snath M L. Isenberg D A. Double blind कै controlled trial of methylprednisolone infusions in ststemic lupus ervithematosus. Arthritis Rheum 1986: 29: S4t.

7 Lichling M R. McLaughlin K. Boonsuc S, Kasdin J. Barnetle F. V. Monthls pulses of methulprednisolone in SLE nephritis. IS Rheumatol 1982: 9: 543-\$.

\& Mackworth-Young $C^{C}$ G. Walport $M$ J. Hughes $G$ R V Thombocylopenia in a case of systemic lupus erythematosus: repeated administration of "pulse" methilprednisolone. $\mathrm{Br} . / \infty$ Rheumatol 1984: 23: 298-300).

9 Barron K S. Person D A. Brewer E J Jr. Beale M (j. Robson A M. Pulse methylprednisolone therapy in diffuse proliferative lupus nephritis. J Pediatr 1982: 101: 137-41.

10) Tan E M. Cohen A S. Fries J F. et al. The 1982 revised criteria for the classification of systemic lupus erythematosus. Arthritis $\mathbb{Q}$ Rheum 1982: 25: 1271-7

11 Ofuji T. Kurata N. Kinash M. Pulse therapy for lupus nephritis. In: Fukase M. ed. Sistemic lupus erythematosus. Baltimorc: Baltimore University Press. 1980: 361-6. 